\title{
Management of crossing vessels in children and adults: A multi-center experience with the transperitoneal laparoscopic approach
}

\author{
Wojciech Panek, ${ }^{1, A-D}$, T.P.V.M de Jong ${ }^{2, E}$, Tomasz Szydełko ${ }^{1, E}$, Rafał Chrzan ${ }^{3, C-F}$ \\ ${ }^{1}$ Division of Oncology and Palliative Care, Faculty of Health Sciences, Wroclaw Medical University, Poland \\ ${ }^{2}$ Department of Pediatric Urology, UMC-WKZ Utrecht, the Netherlands \\ ${ }^{3}$ Department of Pediatric Urology, Jagiellonian University Medical College, Kraków, Poland \\ A - research concept and design; $\mathrm{B}$ - collection and/or assembly of data; $\mathrm{C}$ - data analysis and interpretation; \\ $D$ - writing the article; $E$ - critical revision of the article; $F$ - final approval of the article
}

\section{Address for correspondence \\ Wojciech Panek}

E-mail: wojtpan84@gmail.com

\section{Funding sources}

None declared

Conflict of interest

None declared

\section{Acknowledgements}

The data collection of the pediatric population for this study was conducted during a scholarship program provided by the European Society for Pediatric Urology to Dr. Wojciech Panek, who visited the Departments of Pediatric Urology in UMC Utrecht and AMC Amsterdam, the Netherlands.

\section{Received on September 30, 2017}

Reviewed on April 10, 2018

Accepted on August 9, 2018

Published online on April 5, 2019

\section{Cite as}

Panek W, de Jong TPVM, Szydełko T, Chrzan R. Management of crossing vessels in children and adults: A multi-center experience with the transperitoneal laparoscopic approach. Adv Clin Exp Med. 2019;28(6)::777-782. doi:10.17219/ acem/94142

DOI

10.17219/acem/94142

\section{Copyright}

Copyright by Author(s)

This is an article distributed under the terms of the Creative Commons Attribution Non-Commercial License (http://creativecommons.org/licenses/by-nc-nd/4.0/)

\section{Abstract}

Background. Crossing vessels (CVs) are common in older children and adults with hydronephrosis but no gold standard exists on how to treat this condition. The final decision is made intraoperatively by the surgeon.

Objectives. To assess the outcome of the laparoscopic dismembered pyeloplasty with translocation of the CVs in children and adults.

Material and methods. Prospectively collected data from 3 departments was reviewed. Inclusion criteria were: 1) a transperitoneal laparoscopic approach; 2) dismembered pyeloplasty; and 3) the same operating pediatric urologist (RC) or urologist (TS). In the case of CVs, pyeloplasty with vessel transposition (children) or with cephalad translocation (adults) was performed. Forty-eight children and 41 adults met these criteria. Patients were divided into 4 groups: children with (group 1A) and without (group 1B) CVs, and adults with (group 2A) and without (group 2B) CVs. Any surgical reintervention at the uretero-pelvic junction (UPJ) was deemed a failure.

Results. The overall reintervention rate was $3 / 48$ (6.25\%) in children and 2/41 (4.9\%) in adults ( $p>0.05)$, and involved the following: 4 endopyelotomies and 1 redo pyeloplasty. Crossing vessels were identified in 28/48 (58\%) children and 12/41 (29\%) adults. The mean operation time was $152 \mathrm{~min}$ in group $1 \mathrm{~A}$ and 161 min in group $2 A(p>0.5)$. Reintervention was needed in $2 / 28$ patients in group $1 A$ and in $1 / 12$ patients in group $2 A(p>0.05)$. There was no difference in the failure rate between group $1 A$ and group $1 B$, nor between group $2 A$ and group $2 B(p>0.05)$.

Conclusions. Crossing vessels should be meticulously looked for during pyeloplasty in older children and adults. Dismembered laparoscopic pyeloplasty (LP) with dorsal transposition or cephalad translocation are comparable methods in terms of success rate for the treatment of UPJ obstruction in these patients.

Key words: laparoscopic, hydronephrosis, pyeloplasty, UPJO 


\section{Introduction}

A wide range of acquired and congenital conditions can lead to dilation of the renal collecting system. Uretero-pelvic junction (UPJ) stenosis is the most common cause of hydronephrosis in the pediatric population, with a prevalence between $1: 750$ and 1:1,500, and a male to female ratio of 2:1. ${ }^{1,2}$ Impaired transmission of the peristaltic waves due to abnormal development of the smooth muscles and connective tissue, intraureteral valves and polyps are intrinsic reasons for obstruction. ${ }^{3,4}$ Crossing vessels (CVs), adhesions around the UPJ and kinking of the proximal ureter are among the extrinsic factors. ${ }^{2}$ Furthermore, infections, stones and iatrogenic trauma can also deteriorate the urinary outflow from the renal pelvis.

Lower pole CVs are reported in 11-15\% of young and up to $58 \%$ of older symptomatic children with hydronephrosis., ${ }^{5,6}$ In adults, CVs are present intraoperatively in $39-71 \%$ of all patients operated on due to UPJ obstruction. ${ }^{2}$ It is still unclear whether these vessels can be the sole reason for obstruction or if this entity coexists with the intrinsic pathology.

Dismembered pyeloplasty, described by Kuster and popularized by Anderson and Hynes, is the gold standard surgical treatment for UPJ stenosis. ${ }^{7}$ Laparoscopic pyeloplasty (LP) was first performed in 1993 in adults and in 1995 in children, and over the years, it has almost replaced the open technique in both groups. ${ }^{8-10}$ Nowadays, LP can also be safely done in very young children. ${ }^{3,11}$ When CVs are found during surgery, additional maneuvers are performed to keep the vessels away from the UPJ. However, there is no consensus on how to deal with this finding and the operating surgeon usually makes the final decision intraoperatively.

The goal of the study it to assess the outcome of laparoscopic dismembered pyeloplasty with translocation of the CVs in children and adults.

\section{Material and methods}

\section{Patients}

A retrospective analysis of the prospectively collected data from 3 departments -2 pediatric urology centers and 1 department of urology - was conducted. Inclusion criteria were as follows: 1) a transperitoneal laparoscopic approach without conversion in all patients; 2) dismembered Anderson-Hynes pyeloplasty in all patients; and 3) the same operating pediatric urologist (RC) for children or urologist (TS) for adults, each using one method for CVs management. Children with CVs (group 1A) and adults with CVs (group 2A) were selected. The control groups consisted of the remaining patients without CVs: group $1 B$ - children and group $2 \mathrm{~B}$ - adults.

Clinical symptoms of obstruction (pain, hypertension), worsening of hydronephrosis on repeated ultrasounds, and renal function impairment revealed on the diuretic renography (DR) are the indications for surgical treatment according to the existing recommendations. ${ }^{12}$ In some centers, a cumulative curve with a prolonged half-time to tracer clearance $(\mathrm{T} 1 / 2>20 \mathrm{~min})$ and an excretory urography (IVP) are also used to confirm the diagnosis. ${ }^{2,13}$

In this study, the follow-up was longer than 12 months for all patients (range: 1-9 years). In children, the first ultrasound after pyeloplasty was done 4-6 weeks after removal of the double J catheter (JJC) and then at 3-6-month intervals. A DR was done only in selected cases: symptomatic patients and/or increased dilation on ultrasound. In adults, the first ultrasound and DR are performed 6 weeks after removal of the JJC and then 1 year later.

Complications were classified according to Clavien-Dindo criteria. ${ }^{14}$ A short-term complication is defined as any unsolicited event before the JJC removal. Special attention was paid to any temporary diversion or secondary procedure due to persistent UPJ obstruction after JJC removal, which was classified as a late-term complication. Fisher's exact test was used for the statistical analysis.

\section{Surgical technique}

\section{Children}

Diagnostic cystoscopy and antegrade pyelography are done first and a Foley catheter is left in the bladder. Antegrade pyelography was performed for 2 reasons: to assess the distal part of the ipsilateral ureter and to measure the length of the ureter from the orifice to the UPJ. As the JJC is introduced in the antegrade manner and the length of the ureter in children varies from 12 to $26 \mathrm{~cm}$, it is important to estimate the proper length of the stent beforehand. The patient is turned in the supine position with a $30^{\circ}$ elevation of the affected site. The first trocar is put in the umbilicus in the open manner. A pneumoperitoneum is created and then 2 working trocars are introduced under direct visual control. The pressure is between $8 \mathrm{~mm} \mathrm{Hg}$ and $12 \mathrm{~mm} \mathrm{Hg}$, depending on the age. For the right-sided pyeloplasty, the colon is mobilized and for the left-sided one, a transmesocolic approach is preferred. The renal pelvis and the proximal ureter are exposed and isolated. Crossing vessels are looked for. After transection of the renal pelvis $1 \mathrm{~cm}$ above the UPJ, the narrow part of the ureter is excised and the proximal ureter is spatulated. The posterior wall of the anastomosis is done with interrupted 5-0 sutures (polyglactin). Then, a JJC catheter (4.0 of $4.7 \mathrm{Fr}$ ) is placed percutaneously and finally the anastomosis is completed. The Foley catheter is removed on the $1^{\text {st }}$ day and the JJC 3 weeks later.

\section{Adults}

The main steps of the procedure are similar in adults, although a 5 or 7 Fr JJC are put in a retrograde manner during cystoscopy if technically possible. In a $45 \%$ supine 
position, the first $10 \mathrm{~mm}$ trocar for the camera is put just below the umbilicus. Then, a pneumoperitoneum to $12 \mathrm{~mm} \mathrm{Hg}$ is created and the other working $5 \mathrm{~mm}$ working trocars are inserted. A transmesocolic approach on the left side is used in non-obese patients. During mobilization of the renal pelvis and the proximal ureter, the CVs are looked for. Then, the pelvis wall is transected diagonally from the medial to the lateral edge. Next, the UPJ and the upper part of the ureter are incised downward laterally over the length of $1.5 \mathrm{~cm}$ and the stenotic part is resected. The anastomosis between the pelvis and the spatulated ureter is performed with 4-0 sutures. A wound drain is left next to the anastomosis and removed 3 days after the procedure. The Foley catheter is retrieved after 2 days and the JJC 4-6 weeks postoperatively.

\section{Crossing vessels management}

Dorsal transposition of the CVs is performed in children (Fig. 1,2). In adults, cephalad translocation is done. For this maneuver, the crossing vein is ligated and transected, and the crossing artery is fixed using 2 or $3-0$ absorbable sutures to the Gerota fascia. The sutures with perivascular tissue are applied to preserve the arcuate run of the artery and to avoid postoperative arterial hypertension (Fig. 3,4).

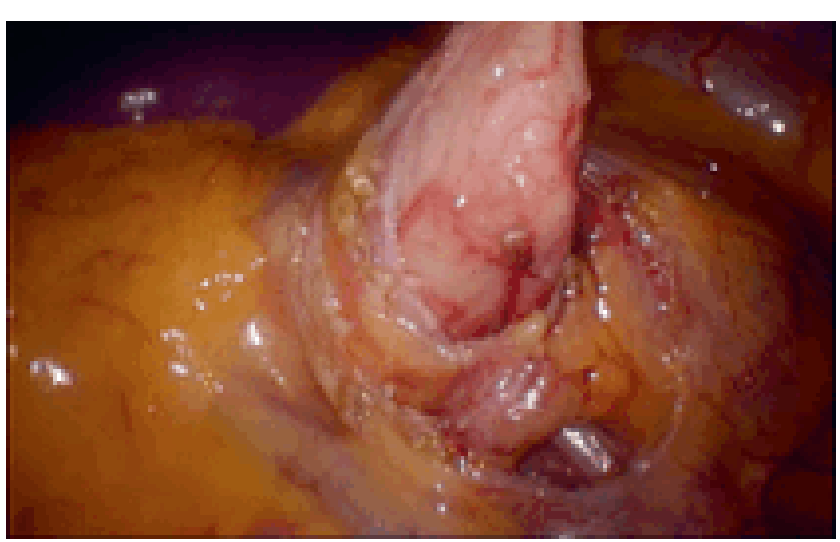

Fig. 1. Dorsal transposition of crossing vessels (CVs): intraoperative view before transection of the ureter. Crossing vessel in front of the ureter

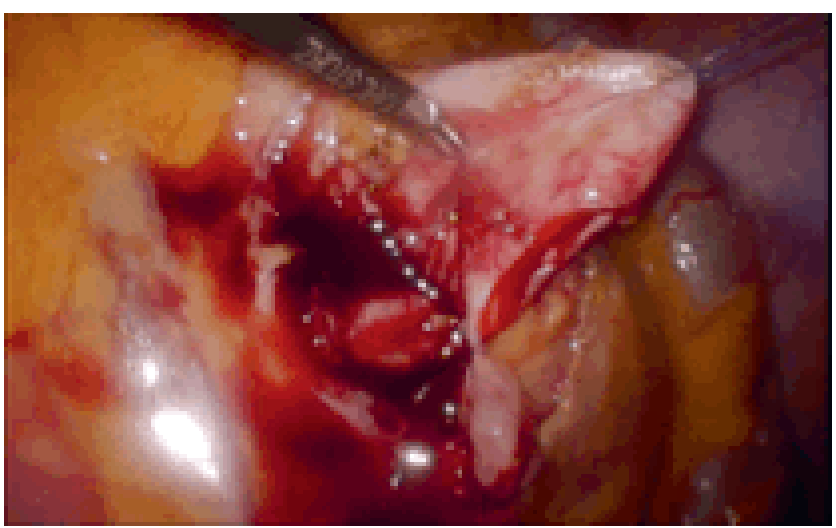

Fig. 2. Dorsal transposition of crossing vessels (CVs): intraoperative view after transection of the ureter and placing of the first stitch

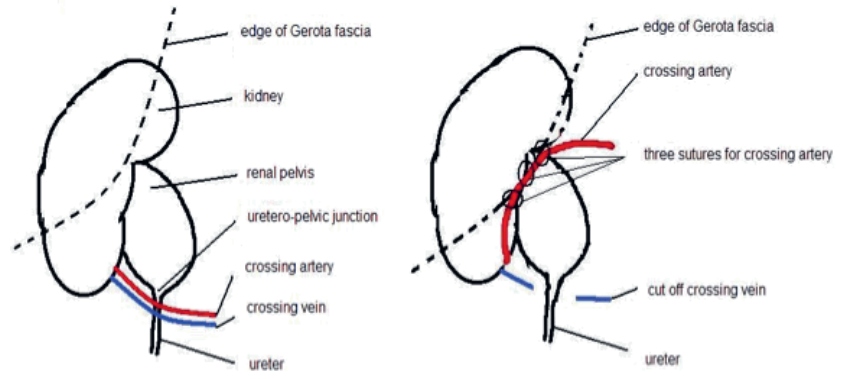

Fig. 3. Sequential steps of cephalad translocation maneuver

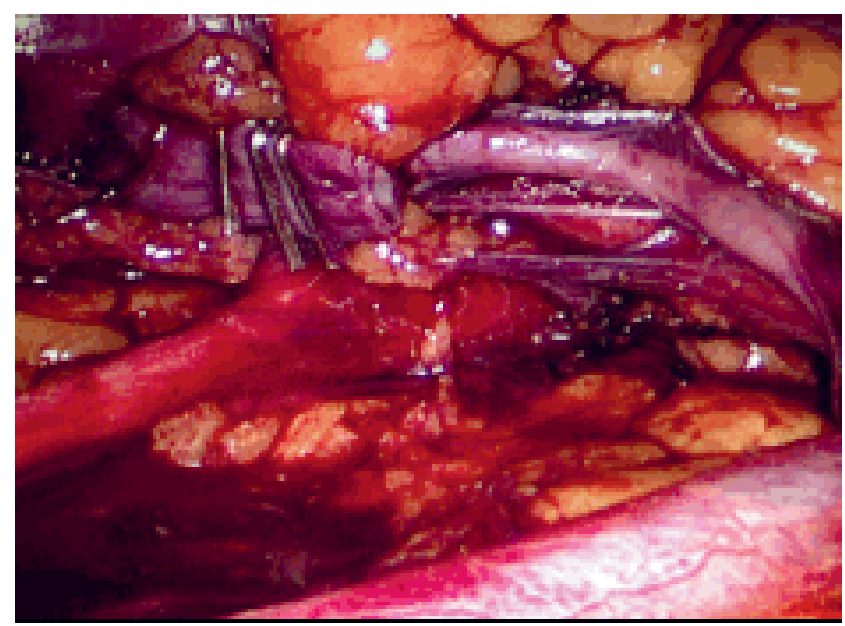

Fig. 4. Translocated crossing artery and cut off crossing vein (adult)

\section{Results}

In all, 76 consecutive LPs in children and 71 LPs in adults were analyzed. Forty-eight children and 41 adults met the inclusion criteria. The mean age was 9.9 years (mode - 5.1 years, range: $3.0-17.7$ years) and 35.5 years (mode -30.5 years, range: $18-72$ years), respectively. The mean follow-up was 4.2 years (range: $1-9$ years) for children and 2.6 years (range: $1-4$ years) for adults. Twenty-eight children and 12 adults had CVs. The patients' characteristics are presented in Table 1 . The mean operative time was $150 \mathrm{~min}$ in children and $161 \mathrm{~min}$ in adults (Table 2).

Table 1. Patients' data

\begin{tabular}{|c|c|c|c|}
\multicolumn{2}{|c|}{ Variables } & Children $(\mathrm{n}=48)$ & Adults $(\mathrm{n}=41)$ \\
\hline \multirow{3}{*}{ Gender } & female & $17(35.4 \%)$ & $28(68.3 \%)$ \\
\cline { 2 - 5 } & male & $31(64.6 \%)$ & $13(31.7 \%)$ \\
\hline \multirow{3}{*}{ Side } & left & $28(58.3 \%)$ & $17(41.5 \%)$ \\
\cline { 2 - 4 } & right & $20(41.7 \%)$ & $24(58.5 \%)$ \\
\hline \multirow{3}{*}{ CVs } & yes & $28(58.3 \%)$ & $12(29.3 \%)$ \\
\cline { 2 - 4 } & left side & 17 & 3 \\
\hline
\end{tabular}

CVs - crossing vessels. 
Table 2. Mean operative time

\begin{tabular}{|c|c|c|c|c|}
\hline Variables & Children & Mean operative time [min] & Adults & Mean operative time [min] \\
\hline CVs & IA & 152 & (cephalad translocation) \\
\hline No CVS & (dorsal transposition) & 149 & IIB \\
\hline
\end{tabular}

CVs - crossing vessels.

Table 3. Characteristic of short- and long-term complications in both groups

\begin{tabular}{|c|c|c|c|}
\hline Complication & C-D & Number of cases & Solution \\
\hline \multicolumn{4}{|c|}{ Children } \\
\hline \multicolumn{4}{|c|}{ Short-term } \\
\hline Prolonged postoperative pain & 1 & $2(4.2 \%)$ & painkillers \\
\hline Leakage of urine and peritonitis & $\| l l b$ & $1(2.0 \%)$ & percutaneous peritoneal drainage and change of the JJC; no UPJ intervention \\
\hline Pelvic dilation and pain & $\| l l b$ & $1(2.0 \%)$ & nephrostomy tube placement, no UPJ intervention \\
\hline \multicolumn{4}{|c|}{ Long-term } \\
\hline Chronic abdominal pain & IIIb & $1(2.0 \%)$ & JJC placement; no UPJ intervention \\
\hline Pain and dilation & IIlb & $3(6.2 \%)$ & endopyelotomy (1 patient had pyeloplasty redone afterwards) \\
\hline \multicolumn{4}{|r|}{ Adults } \\
\hline \multicolumn{4}{|c|}{ Short-term } \\
\hline Pain/pyelonephritis & IIla & $4(9.7 \%)$ & $\mathrm{JJC}$ replacement \\
\hline Bleeding from the skin wound & IIla & $1(2.4 \%)$ & wound inspection and hemostasis \\
\hline \multicolumn{4}{|c|}{ Long-term } \\
\hline Pain and dilation & $\| l l b$ & $2(4.9 \%)$ & undopyelotomy \\
\hline
\end{tabular}

C-D - Clavien-Dindo classification; JJC - double J catheter; UPJ - uretero-pelvic junction.

Complications occurred in $8(16.6 \%)$ pediatric patients. Three patients needed reinterventions due to persistent UPJ obstruction over the long-term. Endopyelotomy was performed in all of these patients and 1 of them required a redo pyeloplasty due to failure of the endoscopic procedure. Two of those 3 patients had CVs. One patient, with chronic abdominal pain and moderate dilation, temporarily received a JJC 5 years after pyeloplasty to exclude UPJ obstruction (Table 3).

There were 7 (17\%) complications in the adult group. Four patients needed the JJC changed under local anesthesia over the short-term. In 1 patient, prolonged bleeding from the wound required surgical exploration. None of those patients needed a secondary procedure on the UPJ. Two patients needed surgical reintervention due to persistent UPJ obstruction over the long-term (endopyelotomy). One of them had CVs. The mean time to the second surgical treatment was 5.33 months in children and 34.5 months in adults $(\mathrm{p}=0.29)$. In patients with CVs, it was 3 months

Table 4. Reinterventions in relation to crossing vessels (CVs) management

\begin{tabular}{|l|c|c|}
\hline \multicolumn{1}{|c|}{ CVs } & Children $(\boldsymbol{n}=48)$ & Adults $(\boldsymbol{n}=41)$ \\
\hline Yes & dorsal transposition & cephalad translocation \\
& $1 \mathrm{~A}-2 / 28(7.1 \%)$ & $2 \mathrm{~A}-1 / 12(8.3 \%)$ \\
\hline No & $1 \mathrm{~B}-1 / 20(5.0 \%)$ & $2 \mathrm{~B}-1 / 29(3.4 \%)$ \\
\hline
\end{tabular}

vs 25 months, respectively. The overall success rate over the long-term was $92.9 \%$ in patients after LP with dorsal transposition of the CVs (group 1A) vs $91.7 \%$ in patients after LP with cephalad translocation (group 2A) (Table 4).

\section{Discussion}

Ureteropelvic junction obstruction is the most common congenital abnormality of the ureter that leads to hydronephrosis, which has a wide spectrum of signs and symptoms. Nowadays, hydronephrosis is usually diagnosed during antenatal screening, but only $10-25 \%$ of these patients need surgical treatment - referred to as a pyeloplasty. ${ }^{1}$ The main goal of the treatment is to relieve the symptoms and to protect the affected kidney from damage and loss of function.

A few epidemiological discrepancies between our cohort and the data from the literature were found. The CVs were identified only in $29 \%$ of adult patients, which is a rather low prevalence, compared to $39-71 \%$, as published by Leavitt et al. ${ }^{15}$ Furthermore, the CVs were more common in adult female patients $(68.3 \%)$ and on the right side, while other authors claim the CVs present more often in men and on the left side. ${ }^{1,15}$ The characteristics of our pediatric population have comparable distribution to the other series. ${ }^{16-18}$ We analyzed the consecutive procedures performed by 2 experienced laparoscopic surgeons employing 
the transperitoneal approach, which theoretically should minimize the risk that the CVs were overlooked.

Dismembered pyeloplasty with excision of the UPJ region, as proposed by Kusters and modified by Anderson and Hynes, has become the gold standard procedure for treating UPJ stenosis. Non-dismembered methods (Fenger, Foley, Y-V, Culp and DeWeerd's, Scardino and Prince), as well as endoscopic endopyelotomy, have also been developed, but they were found to be less effective. ${ }^{19}$ The laparoscopic technique was introduced in adults in 1993 and 2 years afterwards in children. Over time, it has been proven to be at least as effective as the open technique, providing less morbidity, shorter postoperative hospital stays and better cosmetic outcomes. ${ }^{20,21}$ Transperitoneal and retroperitoneal approaches have similar outcomes and are used depending on the urologist's preferences. ${ }^{17}$ In our cohort, $5 \%$ of adult patients and $6 \%$ of children needed secondary intervention on the UPJ after transperitoneal dismembered LP, which is comparable with the other series, as published by Seixas-Mikelus et al. ${ }^{18}$

Intrinsic stenosis is the most common underlying pathology leading to obstruction. Extrinsic factors (e.g., CVs) can also play a role, but to this day, it is not clear if the CVs are the sole factor causing obstruction. This implies that there is no consensus on how to deal with this intraoperative finding. Dismembered pyeloplasty with dorsal transposition of the CVs is one of the options. ${ }^{22,23}$ However, since Hellström first described the "vascular hitch" in 1949, many surgeons prefer this method in adults and children. ${ }^{24-28}$ Simforoosh et al. published his experience with cephalad translocation of the CVs in children and adults with good outcomes in more than $90 \%$ of cases. ${ }^{16,29}$ Blanc et al. showed a $95 \%$ success rate for retroperitoneal LP with posterior transposition in pediatric patients. ${ }^{30}$ We had a similar success rate of posterior transposition in children and cephalad translocation in adults using the transperitoneal approach.

In our cohort, all patients had an Anderson-Hynes type dismembered pyeloplasty using the same approach and we believe that it is the strongest point of our research. An additional maneuver was used to fix the CVs. The CVs were translocated in different ways but in the same manner in each age group by the same surgeon. No statistically significant differences were found between groups with and without CVs in children and adults. We observed a similarly low number of secondary interventions due to persistent UPJ obstruction after LP with dorsal transposition in children and cephalad translocation in adults. Our analysis revealed shorter time to reintervention after failed LP in children. We cannot explain this phenomenon but it could be related, on the one hand, to more reliable follow-up in children, and, on the other hand, a tendency to postpone the reintervention with an attempt to solve a problem with an internal diversion using a JJC in adults.

The mean operative time was similar in all groups - $150 \mathrm{~min}$ in children and $160 \mathrm{~min}$ in adults - indicating that in experienced hands, the additional maneuvers to handle the CVs do not hinder the procedure. The operative time of LP in pediatric patients varies depending on the series. Blanc et al. published his experience with retroperitoneal LP and the mean duration was $185 \mathrm{~min}$ (range: 160-235 min). ${ }^{30}$ The operative time using the transperitoneal approach presented by van der Toorn et al. was 177 min (range: $115-324 \mathrm{~min}$ ). ${ }^{31}$ Transposition of the CVs was done for adults, but the authors did not differentiate between patients with and without CVs. In our series, the mean operation time is comparable to this data. Furthermore, the additional maneuver to fix the crossing vessels does not significantly prolong the surgery.

The obvious limitation of our paper is the low number of patients. We are also aware that there are many factors that can influence the final outcome of a pyeloplasty: the method, the approach and the technique, as well as the manner of suturing and stenting. Furthermore, comparison of a different surgical technique in the different age groups could be confusing and is statistically not justified. To minimize the bias in both groups, only patients who had the Anderson-Hynes procedure done by the same surgeon and using the transperitoneal approach were selected. In case of CVs, an additional maneuver was used to fix the problem. The results have been assessed in relation to the those who had no CVs - in the pediatric or the adult population, respectively. Hence, we compare the outcome of the dismembered pyeloplasty with transposition of the CV done in a slightly different manner.

We can conclude that LP combined with cephalad translocation, as compared to with dorsal transposition, provide the same results as LP alone when no CVs are present. Another limitation of our study involves the diagnostic and follow-up protocols, which are not the same in children and adults. However, only 1 protocol was consistently used in each group. Finally, the Clavien-Dindo classification may be misleading when used for the pediatric and adult populations. Similar complications that are solved in a comparable manner have a different grade of severity because of the need for general anesthesia (e.g., to insert/ change a JJC) in children.

\section{Conclusions}

Crossing vessels should be meticulously looked for during pyeloplasty in older children and adults. Dismembered LP with dorsal transposition or cephalad translocation are comparable methods in terms of success rate for treatment of UPJ obstruction in those patients.

\section{References}

1. Fefer S, Ellsworth P. Prenatal hydronephrosis. Pediatr Clin North Am. 2006;53(3):429-447.

2. Hashim H, Woodhouse CRJ. Ureteropelvic junction obstruction. European Urology Supplements: Official Journal of the European Association of Urology. 2012;11(2):25-32. 
3. Menon P, Rao KLN, Sodhi KS, Bhattacharya A, Saxena AK, Mittal BR. Hydronephrosis: Comparison of extrinsic vessel versus intrinsic ureteropelvic junction obstruction groups and a plea against the vascular hitch procedure. J Pediatr Urol. 2015;11(2):80.e1-6.

4. Szydelko T, Apoznanski W, Koleda P, Rusiecki L, Janczak D. Laparoscopic pyeloplasty with cephalad translocation of the crossing vessel - a new approach to the Hellström technique. Wideochir Inne Tech Maloinwazyjne. 2015;10(1):25-29.

5. Singh RR, Govindarajan KK, Chandran H. Laparoscopic vascular relocation: Alternative treatment for renovascular hydronephrosis in children. Pediatr Surg Int. 2010;26(7):717-720.

6. Cain MP, Rink RC, Thomas AC, Austin PF, Kaefer M, Casale AJ. Symptomatic ureteropelvic junction obstruction in children in the era of prenatal sonography: Is there a higher incidence of crossing vessels? Urology. 2001;57(2):338-341.

7. Anderson JC, Hynes W: Retrocaval ureter: A case diagnosed preoperatively and treated successfully by a plastic operation. Br J Urol. 1949;21(3):209.

8. Schuessler WW, Grune MT, Tecuanhuey LV, Preminger GM. Laparoscopic dismembered pyeloplasty. J Urol. 1993;150(6):1795-1799.

9. Peters CA, Schlussel RN, Retic AB. Pediatric laparoscopic dismembered pyeloplasty. J Urol. 1995;153(6):1962-1965.

10. Knoedler J, Han L, Granberg C, et al. Population-based comparison of laparoscopic and open pyeloplasty in pediatric pelvi-ureretic junction obstruction. BJU Int. 2013;111(7):1141-1147.

11. García-Aparicio L, Blazquez-Gomez E, Martin O, et al. Pyeloplasty in patients less than 12 months old. Is the laparoscopic approach safe and feasible? J Endourol. 2014;28(8):906-908.

12. Tekgül S, Dogan HS, Erdem E, et al. Guidelines on Paediatric Urology. European Association of Urology Guidelines; 2015:43. https://uroweb. org/wp-content/uploads/EAU-Guidelines-Paediatric-Urology-2015. pdf.

13. Szydełko T, Kasprzak J, Lewandowski J, Apoznański W, Dembowski J. Dismembered laparoscopic Anderson-Hynes pyeloplasty versus non-dismembered laparoscopic $\mathrm{Y}-\mathrm{V}$ pyeloplasty in the treatment of patients with primary ureteropelvic junction obstruction: A prospective study. J Endourol. 2012;26(9):1165-1170.

14. Dindo D, Demartines N, Clavien PA. Classification of surgical complications: A new proposal with evaluation in a cohort of 6336 patients and results of a survey. Ann Surg. 2004;240(2):205-213.

15. Leavitt DA, Nicholson AF, Ortiz-Alvarado O, et al. Nature of crossing vessels in patients with radiographically normal ureteropelvic junctions: Prevalence and anatomic characteristics. Urology. 2013;81(6): 1168-1172.

16. Simforoosh N, Tabibi A, Nouralizadeh A, Nouri-Mahdavi K, Shayaninasab H. Laparoscopic management of ureteropelvic junction obstruction by division of anterior crossing vein and cephalad relocation of anterior crossing artery. J Endourol. 2005;19(7):827-830.

17. Badawy H, Zoair A, Ghoneim T, Hanno A. Transperitoneal versus retroperitoneal laparoscopic pyeloplasty in children: Randomized clinical trial. J Pediatr Urol. 2015;11(3):122.e1-6.
18. Seixas-Mikelus SA, Jenkins LC, Williot P, Greenfield SP. Pediatric pyeloplasty: Comparison of literature meta-analysis of laparoscopic and open techniques with open surgery at a single institution. J Urol. 2009;182(5):2428-2432.

19. Carr MC, El-Ghoneimi A. Anomalies and surgery of the ureteropelvic junction in children. In: Wein AJ, Novick AC, Partin A, Peters CA, eds. Campbell-Walsh Urology, Vol. $49^{\text {th }}$ ed. Philadelphia, PA: Elsevier Saunders; 2007:3370.

20. Autorino R, Eden C, El-Ghoneimi A, et al. Robot-assisted and laparoscopic repair of ureteropelvic junction obstruction: A systematic review and meta-analysis. Eur Urol. 2014;65(2):430-452.

21. Moon DA, El-Shazly MA, Chang CM, Gianduzzo TR, Eden CG. Laparoscopic pyeloplasty: Evolution of a new gold standard. Urology. 2006; 67(5):932-936.

22. Türk IA, Davis JW, Winkelmann B, et al. Laparoscopic dismembered pyeloplasty: The method of choice in the presence of an enlarged renal pelvis and crossing vessels. Eur Urol. 2002;42(3):268-275.

23. Inagaki T, Rha KH, Ong AM, et al. Laparoscopic pyeloplasty: Current status. BJU Int. 2005;95(Suppl 2):102-105.

24. Meng MV, Stoller ML. Hellström technique revisited: Laparoscopic management of ureteropelvic junction obstruction. Urology. 2003; 62(3):404-408

25. Zhang X, Xu K, Fu B, et al. The retroperitoneal laparoscopic Hellström technique for pelvi-ureteric junction obstruction from a crossing vessel. BJU Int. 2007;100(6):1335-1338.

26. Gundeti MS, Reynolds WS, Duffy PG, Mushtaq I. Further experience with the vascular hitch (laparoscopic transposition of lower pole crossing vessels): An alternate treatment for pediatric ureterovascular ureteropelvic junction obstruction. J Urol. 2008;180(4 Suppl): 1832-1836.

27. Schneider A, Ferreira CG, Delay C, Lacreuse I, Moog R, Becmeur F. Lower pole vessels in children with pelviureteric junction obstruction: Laparoscopic vascular hitch or dismembered pyeloplasty? J Pediatr Urol. 2013;9(4):419-423.

28. Singh RR, Govindarajan KK, Chandran H. Laparoscopic vascular relocation: Alternative treatment for renovascular hydronephrosis in children. Pediatr Surg Int. 2010;26(7):717-720.

29. Simforoosh $\mathrm{N}$, Javaherforooshzadeh A, Aminsharifi A, Soltani MH, Radfar MH, Kilani H. Laparoscopic management of ureteropelvic junction obstruction in pediatric patients: A new approach to crossing vessels, crossing vein division, and upward transposition of the crossing artery. J Pediatr Urol. 2010;6(2):161-165.

30. Blanc T, Muller C, Abdoul H, et al. Retroperitoneal laparoscopic pyeloplasty in children: Long-term outcome and critical analysis of 10-year experience in a teaching center. Eur Urol. 2013;63(3):565-572.

31. van der Toorn F, van den Hoek J, Wolffenbuttel KP, Scheepe JR. Laparoscopic transperitoneal pyeloplasty in children from age of 3 years: Our clinical outcomes compared with open surgery. J Pediatr Urol. 2013;9(2):161-168. 